\title{
Intracellular Recording of the Convergence of Input upon Neurons in Cat Association Cortex
}

\author{
R. Dubner and L. T. Rutledge ${ }^{1}$ \\ Department of Physiology, University of Michigan, Ann Arbor, Michigan
}

Received February 23, 1965

Intracellular responses in anterior middle suprasylvian gyrus to peripheral stimuli (light flash, auditory click, and contralateral forepaw shock) and central stimuli (contralateral cortical and thalamic stimulation) were studied in cats anesthetized with chloralose. When cells discharged to peripheral and some central stimuli, spikes arose from asynchronous, summating, depolarizing postsynaptic potentials of 20 - to $80-\mathrm{msec}$ duration. Long-duration $(30-300 \mathrm{msec})$ hyperpolarizing potentials also were evoked by one or more peripheral and central stimuli in over onethird of cells studicd, and rcpresent inhibitory activity at the rccorded ccll or at previous central synapses. In many instances, cortical inhibitory mechanisms were responsible for blocking effects during interactions between pairs of stimuli. However, when light flash was the conditioning stimulus, the block usually occurred before the recorded cell, either in cortex, or possibly in precortical areas of neuronal convergence. The data indicate that this portion of suprasylvian gyrus in the cat is unequally responsive to various stimuli, with different synaptic patterns of activity evoked by photic and other peripheral and central inputs.

\section{Introduction}

In an earlier study on unit activity in the anterior part of middle suprasylvian gyrus in the cat, it was reported that neurons were unequally responsive to different peripheral and central inputs (14). The majority of cells were responsive to diffuse light flash alone, or to photic stimulation and other sensory stimuli (auditory or somatosensory). During unit interactions between pairs of sensory stimuli, long-duration $(100-300 \mathrm{msec})$ blocking effects were apparent and were suggestive of inhibitory rather than occlusive mechanisms.

Polysensory convergence upon single neurons also has been observed in the thalamus $(3,9,29)$ and other portions of the neuraxis, e.g., the brain-

1 This investigation was supported by grant NB-04119-02 from the National Institute of Neurulogical Disease and Blindness. The technical assistance of Joyce A. Duncan is gratefully acknowledged. Dr. Dubner's present address is: National Institutes of Health, National Institute of Dental Research, Bethesda, Maryland. 
stem reticular formation $(4,7)$. It has been suggested that heterogeneous interactions occur at the thalamic level with the resulting output relayed via common pathways to association cortex $(3,36,37)$. The unequal responsiveness of cells in association cortex may be the result of such precortical sensory interactions or the result of interactions at the cortical level. The purpose of the present study was to determine the role of cortical inhibitory mechanisms during polysensory interactions in the anterior part of middle suprasylvian gyrus of the cat and to record the synaptic patterns of activity evoked by peripheral and central sources of input (13).

\section{Methods}

Acute experiments were performed on fifty-seven cats anesthetized with chloralose $(50 \mathrm{mg} / \mathrm{kg}$, ip). In a few experiments additional chloralose was given intravenously 12-15 hours after the initial dose in order to enhance surface-recorded activity. The suprasylvian gyrus was exposed bilaterally, the dura reflected, and the cortex covered with a pool of mineral oil maintained at body temperature by means of a battery-operated, nichrome wire, oil-bath heater. Rectal temperature was maintained at 36-38 C. Cortical pulsations were reduced by cisternal drainage, bilateral pneumothorax, and by resting a 5-mm plastic pressor-foot with an open center on the surface of the cortex at the recording site. In a few experiments the vertebral column was fixed and suspended at a level approximately that of the exposed cortex. Before the double pneumothorax was performed, the animals were relaxed with gallamine triethiodide (Flaxedil), and the respiration was set at a stroke volume and frequency comparable to the previous respiratory excursions. Though not routinely monitored, alveolar $\mathrm{CO}_{2}$ content was found to be $4.0-5.6 \%$ before artificial respiration and $3.4-5.6 \%$ after the above procedure was carried out. Pupils were dilated in all experiments with one drop of $0.25 \%$ hyoscine solution.

Photic stimulation (5-msec pulse) was produced by a GE 327 tungstenfilament bulb, mounted in a small reflector and driven by a Grass S-4 stimulator. The luminance of the filament was varied by changing the voltage applied to the lamp $(30-80 \mathrm{v})$. The lamp was placed in the midline, $8 \mathrm{~cm}$ in front of the eyes. The luminance of the filament was measured with a Macbeth Illuminometer and ranged from 11.8 to 2832 millilamberts. During most of the experiments a flash of about 450 millilamberts evoked the maximum and least variable surface responses. Background luminance (0.02 millilambert) was supplied by an overhead lamp. When a 60-v, rectangular, $5-\mathrm{msec}$ pulse was applied there was a $2-\mathrm{msec}$ delay to the onset 
of the flash; $3 \mathrm{msec}$ later the pulse ended, and the flash decay time was approximately $40 \mathrm{msec}$. The actual flash duration was $43 \mathrm{msec}$, although during about half of the period its intensity was $10 \%$ or less of maximum.

An audioamplifier and speaker controlled by a Grass S-4 stimulator were used for auditory click stimulation. Click duration was $0.01 \mathrm{msec}$ and the intensity was above threshold necessary to produce evoked responses in primary auditory cortex. Hollow ear bars were used. Two 30-gauge needles were inserted approximately $3 \mathrm{~mm}$ into the foot pad of the contralateral forepaw (CFP) for somesthetic stimulation. The electrical shock $(0.5-\mathrm{msec}$ pulse, 1.5-mamp intensity) was controlled by a Grass stimulator and isolation unit and a constant current converter. Constant current electrical stimulation (0.1-msec pulse) of the contralateral cortical surface was applied via bipolar silver-ball electrodes placed in an area symmetrical to the recording site. The intensity of the stimulus was necessary to evoke a maximum transcallosal (TCR) or interhemispheric delayed response (IDR). For depth stimulation, concentric bipolar electrodes, constructed from 30-gauge nichrome wire placed within 22-gauge steel tubing, were insulated to within $0.5 \mathrm{~mm}$ of their tip; electrode separation was about $1 \mathrm{~mm}$. All stimuli were given at a rate of $0.3-0.5 / \mathrm{sec}$.

A monopolar silver-ball electrode, partially embedded in the plastic pressor-foot was used to record from the suprasylvian site at frontal 12-14 and lateral 8-10 (21). For intracellular recording, glass micropipettes were filled with $2 \mathrm{M} \mathrm{K}$ Citrate and had resistances of 30-80 megohms. Occasionally $3 \mathrm{M} \mathrm{KCl}$ electrodes were used to invert hyperpolarizing potentials in order to identify them as inhibitory in nature (11). The microelectrode was mounted on a mechanical micromanipulator, inserted within the open center of the pressor-foot, and connected to a high impedance negative capacitance electrometer amplifier. Grid current was adjusted to $10^{-13} \mathrm{amp}$ or less. For surface recordings, potentials were displayed on a multiple beam oscilloscope after amplification by $\mathrm{r}-\mathrm{c}$ coupled amplifiers set at a band pass of 0.8 to $2,000 \mathrm{cycle} / \mathrm{sec}$. For d-c recording, outputs from the electrometer amplifier were led directly to the oscilloscope and to a continuously running Offner Dynograph recorder. The latter was employed to record resting membrane potentials and the duration of successful impalements.

In those experiments that required histological verification of depth electrode placement, the brain was perfused through the heart with $0.9 \%$ saline solution followed by $10 \%$ formalin. The brain was removed immediately and fixed in formalin for 1-6 weeks. Serial frozen sections were then cut and stained by the Nissl technique. 


\section{Results}

General Properties of Cells. Intracellular data were obtained from 253 cells satisfying the following criteria: (a) A negative d-c potential shift of $30 \mathrm{mv}$ or more took place when the electrode impaled the cell and remained stable for $30 \mathrm{sec}$ or more; and (b) characteristic spike potentials of 30-80 mv and slow-wave membrane potential changes (depolarizing, hyperpolarizing) occurred during the impalement. Cells were considered badly damaged and excluded from the analysis when they exhibited high frequency discharge on penetration with rapid deterioration of resting potentials and action potentials, and small spikes with abnormally long duration. Action potentials which did not exhibit slow, graded, synaptic potentials were considered axon spikes (10) and were excluded from the analysis. A number of cells displayed large resting potentials and slow-wave synaptic potentials after spike activity disappeared. These cells have been included in the sample since the time course of synaptic potentials evoked by different inputs did not change after spike inactivation. Successful impalements were found at all cortical levels, though the majority of recordings were from cells $500-1500 \mu$ in depth.

Intracellular recordings for periods of 3-40 min were obtained from 61 of the 253 cells included in the analysis. The resting potential for this group was $50.4 \pm 9.0 \mathrm{mv}$ (mean and standard deviation). If the tip potential of $8-10 \mathrm{mv}$ introduced by the $\mathrm{K}$-citrate electrode is taken into account (1), the value of the resting potential is approximately $60 \mathrm{mv}$. The mean value of the action potential amplitude for this group was $44.4 \pm 12.6 \mathrm{mv}$ (mean and standard deviation), indicating that most of these cells had action potentials which lacked an overshoot.

When cells discharged to a peripheral stimulus, the spikes arose from excitatory postsynaptic potentials of $20-80 \mathrm{msec}$ duration (Fig. 1). The long latency $(20-40 \mathrm{msec})$, long duration, and irregular configuration of these EPSPs suggest their elaboration by multisynaptic, asynchronous activity; thus they are quite different from the synchronous EPSPs found after monosynaptic activation of spinal motoneurons (16). The responses shown in Fig. 1 were graded by changing the stimulus magnitude. An increase in light intensity altered the latency and amplitude of the surface double wave in a manner similar to surface responses recorded in primary visual cortex (8); at the same time the EPSP latency and duration decreased and spike discharge occurred at higher flash intensities. However, it is important to note that the cellular and surface responses to peripheral inputs could be graded in only a few cells by changing the magnitude of 
the stimulus. The cortical area in which the units were found is not sensitive to intensity changes within fairly wide limits. Large changes in intensity and duration of the photic, auditory, or somatic stimulus produced small changes in the surface and cellular responses. The stimulus which evoked the maximum and least variable responses for each peripheral input was employed throughout these experiments.

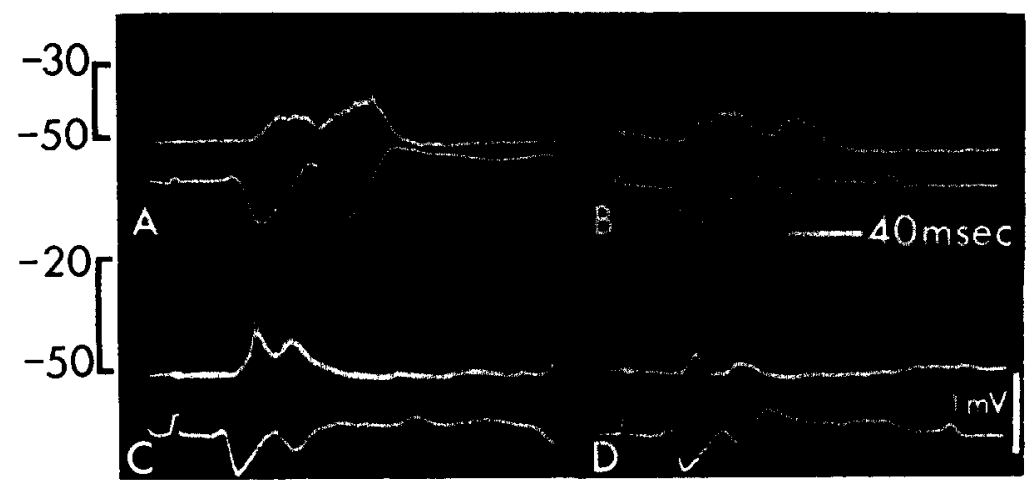

FIG. 1. Graded excitatory responses to photic stimulation. Flash intensity increases from $A$ to D. Stimulus artifact is vertical deflection on lower tracings. Brightness in millilamberts: A, 11.8; B, 74.2; C, 448.4; D, 2076.8. Positive is upward in the intracellular channel (upper tracings) and downward in the surface electrode channel (lower tracings) in this and subsequent illustrations. Voltage calibration is $1 \mathrm{mv}$ for the surface record. The $d-c$ potential levels for the intracellular records are given at the left in millivolts. Baselines in all illustrations have been retouched to remove halos. Spikes have been retouched in this figure.

The time correlation between the surface and intracellular synaptic potentials seen in Fig. 1 was evident in many experiments (Figs. 2, 4-8); the correlation with respect to electrical sign was more variable but consistent for a given cell.

A few cells exhibited only asynchronous EPSPs and no spike discharge in response to a peripheral stimulus (Table 1). The interhemispheric delayed response (IDR) to contralateral cortical stimulation (34) and the cortical response to centromedian nucleus (CM) stimulation also were characterized by spikes arising from asynchronous EPSPs (Figs. 3B, 8).

Short-latency, synchronous EPSPs were found in response to stimulation of the lateralis posterior-pulvinar (LP) complex of the thalamus and to transcallosal stimulation. In Fig. 2 graded synchronous EPSP responses to LP stimulation are illustrated. With increasing stimulus intensity, the EPSP size increased and finally reached threshold for spike discharge. 
Long-duration (30-300 msec) hyperpolarizing potentials were recorded in response to peripheral and central stimuli (Figs. 3A, C; 4A, B). These hyperpolarizations were considered to represent inhibitory activity at the recorded cell or at previous synapses if one or more of the following criteria was observed: (a) The evoked hyperpolarization blocked spike discharge

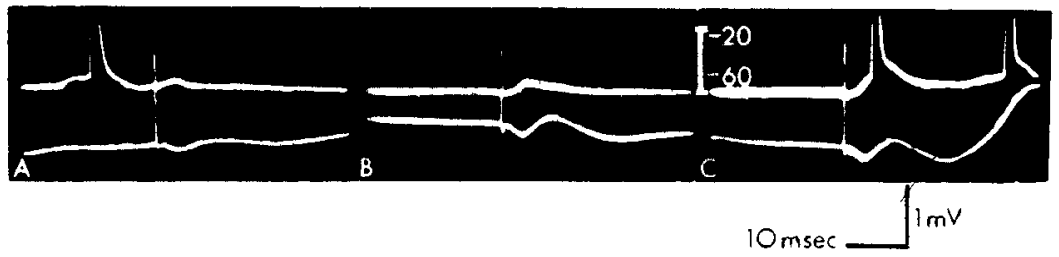

Fir. 2. Short-latency synchronous EPSP responses to LP complex stimulation. Stimulation of LP complex evoked short-latency (1.5-msec) synchronous EPSPs. The EPSP size increased and spike discharge occurred when stimulus intensity was increased. A, 0.3 mamp; B, 0.4 mamp; C, $0.5 \mathrm{mamp}$ (0.25-msec duration for all stimuli). Stimulus artifact is vertical line on all tracings. The $d-c$ potential level in $C$ is for all frames. Voltage calibration is $1 \mathrm{mv}$ for the surface record.

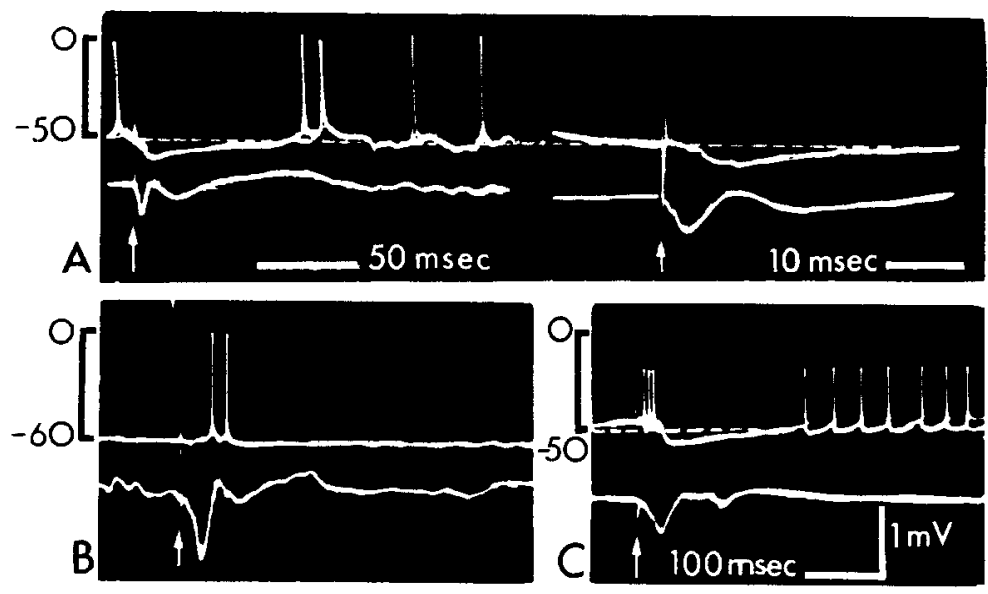

Fig. 3. Intracellular responses to thalamic stimulation. A. Long-duration membrane hyperpolarization evoked by LP complex stimulation, same cell, two different sweep speeds. Latency is $2 \mathrm{msec}$. B. Stimulation of $\mathrm{CM}$ complex evoked an asynchronous EPSP with spike discharge in another cell. C. In another cell, membrane hyperpolarization was evoked by CM complex stimulation and blocked spike discharge. Time calibration is the same in B and C. Voltage calibration is $1 \mathrm{mv}$ for the surface record in all frames. The $d-c$ potential levels for the intracellular channel are given for A, B, and C. Arrows indicate stimulations in this and remaining figures unless otherwise noted. The dashed lines represent the resting membrane potential Jevel. 
and occurred in the absence of preceding spike discharge; (b) EPSPs occurring during the course of the hyperpolarization were of smaller amplitude than those occurring in the absence of hyperpolarization; and (c) hyperpolarization was reduced in amplitude or inverted to a depolarizing postsynaptic potential when chloride-filled electrodes were employed (11). The relative amounts of presynaptic (17) and postsynaptic inhibition (IPSPs) could not be determined utilizing the above criteria. In addition, the
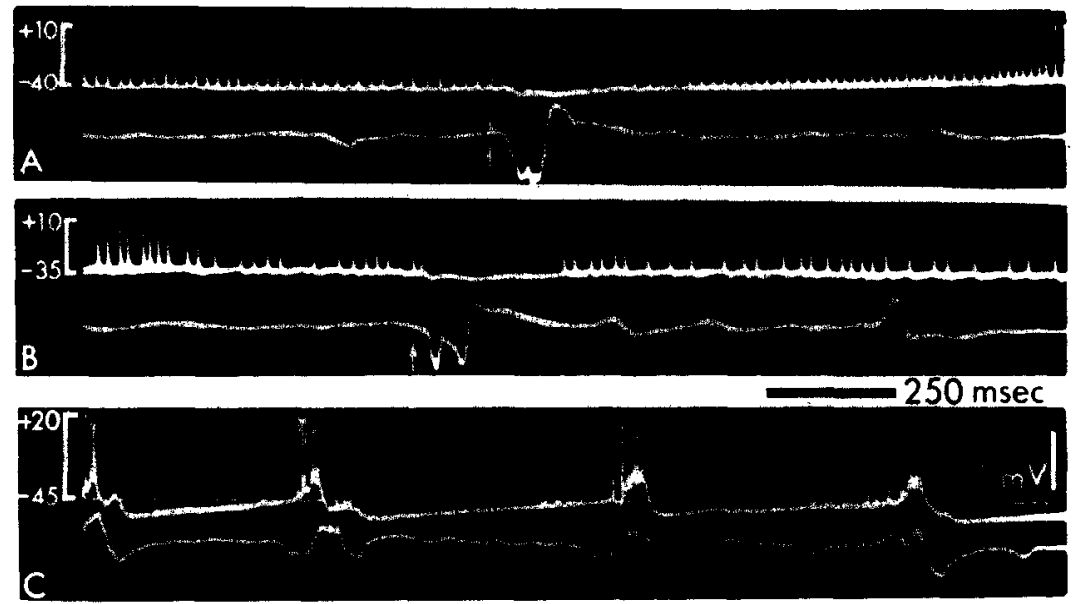

FIG. 4. Evoked and spontaneous membrane hyperpolarization. Photic (A) and auditory (B) stimulation blocked high frequency spike discharge for approximately $250 \mathrm{msec}$. The cell was injured due to impalement. C. Spontaneous, repetitive, burst activity followed by long-duration hyperpo'arization. The $\mathrm{d}-\mathrm{c}$ potential levels are given at the left. Voltage calibration is $1 \mathrm{mv}$ for surface record in A, B and C. Spikes are retouched in $\mathrm{C}$.

presence of hyperpolarization, per se, does not insure that an inhibitory process is occurring at the recorded cell. Hyperpolarization would also result if there was a decrease in excitatory activity converging on the recorded cell due to presynaptic or postsynaptic inhibition at previous synapses. Thus, criterion (a) alone does not conclusively establish the presence of inhibitory processes at the recorded cell. Membrane hyperpolarization evoked by LP complex stimulation and occurring in the absence of preceding spike discharge is illustrated in Fig. 3A. In Figs. 3C, 4A and $4 \mathrm{~B}$, long-duration hyperpolarization evoked by central and peripheral stimulation blocked spontaneous spike discharge.

Changes in EPSP size during membrane hyperpolarization indicate that 
inhibitory mechanisms occurred at the recorded cell, criterion (b), but the additional presence of inhibition at previous synapses cannot be ruled out. Figure 5 illustrates the response of a cell monosynaptically activated by LP complex stimulation. Spike discharge was inhibited by a conditioning photic stimulus which evoked membrane hyperpolarization. In this instance,
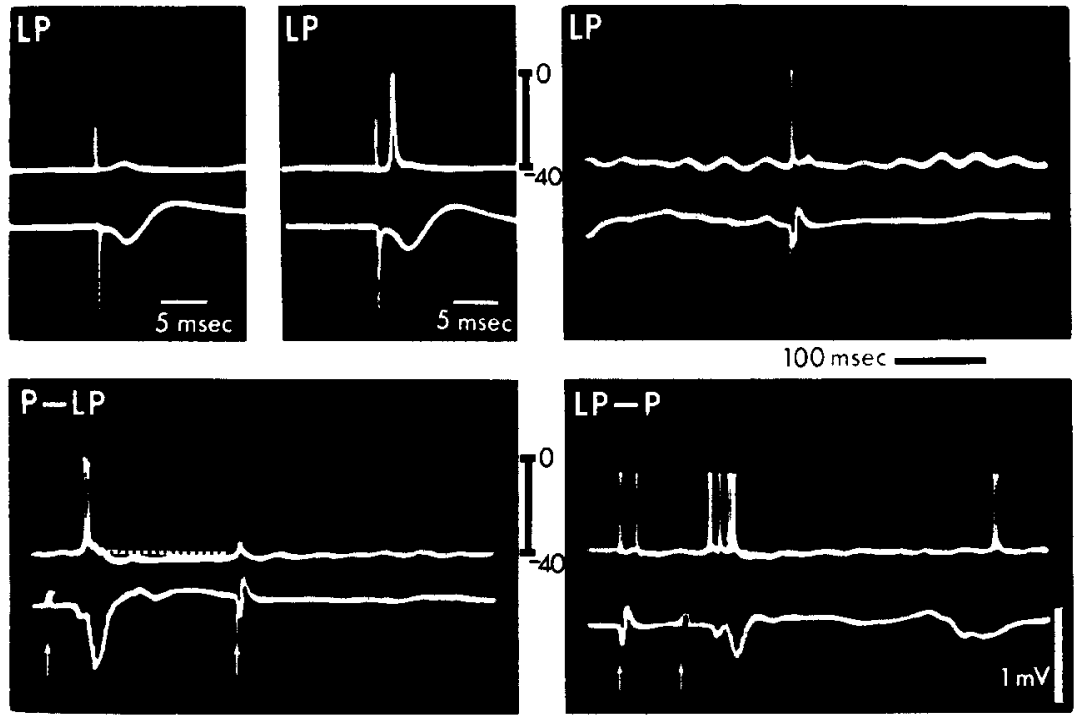

FIG. 5. Inhibitory interaction between photic and thalamic input. Stimulation (0.25 mamp, $0.25 \mathrm{msec}$ ) of LP complex (LP, first frame) evoked a synchronous EPSP with a 1 -msec latency. Increase in stimulus intensity $(0.35 \mathrm{mamp})$ resulted in spike discharge (LP, second and third frames, two different sweep speeds). A conditioning photic stimulus (P) evoked spike discharge, produced slight membrane hyperpolarization, and inhibited spike discharge to LP complex stimulation (P-LP). The conditioningtest interval was $210 \mathrm{msec}$. No blocking of the photic test stimulus occurred during the reverse interaction (LP-P). The d-c calibrations are for the upper level intracellular tracings. Time calibration is $100 \mathrm{msec}$ unless otherwise indicated. Stimulus artifact indicated by arrow in lower frames and by downward deflecting line on lower tracing of upper three frames.

inhibitory mechanisms at the recorded cell were responsible for the blocking effect. Of twenty cells studied with $\mathrm{KCl}$-filled electrodes, criterion (c), two exhibited inversion of hyperpolarizing potentials to depolarizing potentials, in two cells evoked membrane hyperpolarization rapidly disappeared, and in fourteen other cells, no membrane hyperpolarization was observed. Of eighty-six cells in which membrane hyperpolarization was evoked by one or 
more stimuli, seventeen met criteria (b) or (c) or both. Thus $20 \%$ of the hyperpolarizations represented inhibition at the recorded cell.

An inflection on the rising phase of the action potential was observed in only $38 \%$ of cells ( 50 of 131 ) where photographic records permitted such a distinction. Such an inflection apparently reflects threshold differences and conduction delay between the initial segment of the axon and the somadendritic membrane $(10,18)$. The uncommon occurrence of this inflection in association cortex neurons is not unique; it is often missing in spinal cord interneurons (20), thalamic neurons (31), and reticular formation neurons (27).

Depolarizing after-potentials and repetitive firing (22) were observed in relatively few cells. Figure 2 illustrates the response of a cell which exhibited a depolarizing after-potential. In Fig. 4C, spontaneous, repetitive, burst activity is shown followed by long-duration membrane hyperpolarization. The depolarization-hyperpolarization pattern was spontaneously repeated.

Peripherally Originating Input. Only thirty-one cells were fully tested to all peripheral stimuli since the analysis was directed toward interactions between photic and auditory stimuli. The data from these thirty-one cells are comparable to previously reported extracellular data (14). About $75 \%$ of cells ( 23 out of 31 ) were responsive to one or more peripheral inputs and all of the eight monosensory cells discharged to photic stimulation only. In addition, fourteen of the fifteen polysensory cells (responsive to more than one peripheral stimulus) discharged to photic and to one or more of the peripheral stimuli.

In Table 1 the responsiveness to peripheral inputs of 233 cells, impaled with $\mathrm{K}$-citrate-filled electrodes, is tabulated. The results are comparable to the extracellular data. Cells were most responsive to photic input (187 out of 227), with a decreasing order of responsiveness to auditory stimulation (52 out of 99) and somatosensory stimulation (CFP, 12 out of 37). Although care was taken to evoke maximum surface and intracellular responses to each peripheral stimulus, conclusive proof of equal stimulus magnitudes is lacking and therefore any interpretation of this site as a visual association area is limited (14).

The "inhibitory only" and "both" categories in Table 1 show the number of cells which exhibited inhibitory responses to each peripheral input, judged by the above-mentioned criteria for inhibitory potentials. In $37 \%$ of the cells studied ( 86 out of 233 ), one or more stimuli evoked hyperpolarizing potentials. Ninety-two per cent of these hyperpolarizing poten- 
tials persisted in the absence of preceding spike discharge. As mentioned previously, this criteria alone does not establish the presence of inhibitory activity at the recorded cell, although inhibitory interaction has occurred at one or more synapses in the multisynaptic pathway to these cortical neurons. Occlusive mechanisms of $100-300 \mathrm{msec}$ duration are improbable. Analogous to the excitatory data, long-duration hyperpolarizations were evoked most often by photic stimulation, with a decreasing order of inhibi-

TABLE 1

Responsiveness of 233 Cells to Each Peripheral Input DURING INTRACELLULAR RECORDINGS ${ }^{a}$

\begin{tabular}{lccccc}
\hline & & $\begin{array}{c}\text { Excitatory } \\
\text { onlyc } \\
\text { Input }\end{array}$ & $\begin{array}{c}\text { Inhibitory } \\
\text { only } \\
\%\end{array}$ & $\begin{array}{c}\text { Bothe } \\
\%\end{array}$ & $\begin{array}{c}\text { Unresponsive } \\
\%\end{array}$ \\
\hline Photic & 227 & 45.5 & 13 & 23.5 & 18 \\
Auditory & 99 & 27.5 & 11 & 14 & 47.5 \\
CFP & 37 & 27 & 0 & 5.5 & 67.5 \\
\hline
\end{tabular}

a The twenty cells impaled with $\mathrm{KCl}$-filled electrodes are not included in this analysis.

${ }^{b} \mathrm{~N}$ represents the total number of cells studied in each category, e.g., 227 of 233 cells were tested to photic stimulation.

$c$ Includes eleven cells which showed only EPSPs and no spike discharge to one or more peripheral stimuli.

d \% refers to the percentage of cells responding in each category irrespective of whether the cell responded to any other stimulus.

- Some of the cells exhibited both excitatory and inhibitory responses and are listed in the "Both" column.

tory responses found for auditory and somatic stimuli (combined "inhibitory only" and "both" categories). Additional evidence of unequal responsiveness of peripheral input was obtained from the polysensory group of cells studied during intracellular recordings. Thirty-two per cent (18 out of 57 cells tested to photic and auditory stimulation) exhibited different membrane potential changes to photic and auditory stimuli (EPSPs, IPSPs or both). Thus, cells exhibiting spike discharge to two or more peripheral inputs may manifest unequal convergence at the membrane level.

The role of membrane hyperpolarization during blocking interactions was carefully studied. In twenty cells, thirty-six interactions were performed between peripheral inputs (usually photic and auditory). These interactions have been classified into three types, I, II, and III, and are illustrated in Fig. 6. In the type-I interaction, no membrane hyperpolarization was evoked by the conditioning stimulus to explain the long-duration 

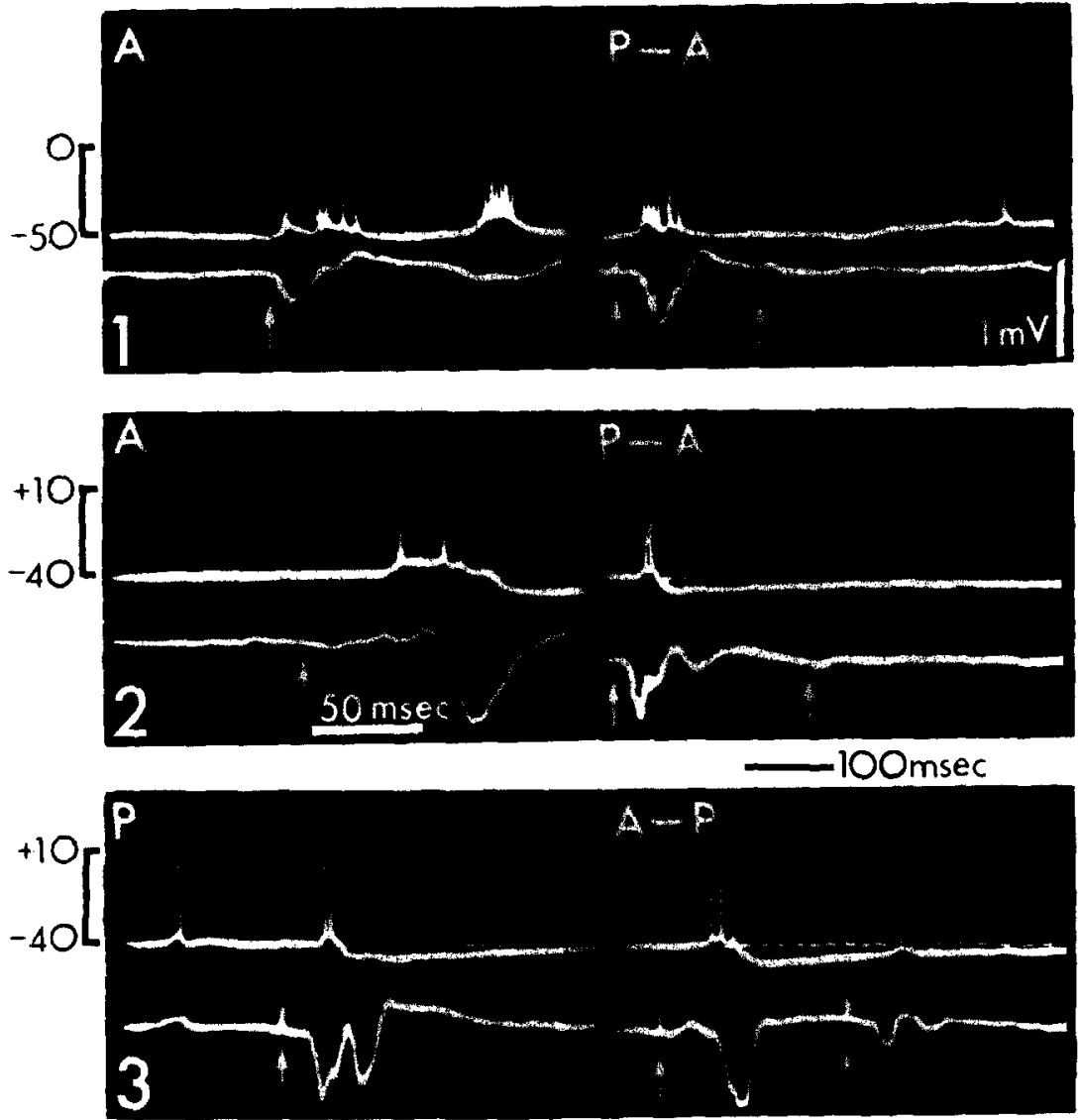

FIG. 6. Interactions between photic (P) and auditory stimulation (A). Responses to the test stimulus alone are shown in the left-hand frames. 1. Type-I interaction. Conditioning photic stimulus blocked the cellular response to auditory stimulation $(\mathrm{P}-\mathrm{A})$. Blocking interval is $150 \mathrm{msec}$. No membrane hyperpolarization was evoked by either input. 2. Type-II interaction. In another cell, photic and auditory stimulation evoked asynchronous EPSPs with spike discharge followed by membrane hyperpolarization. During the interaction ( $\mathrm{P}-\mathrm{A})$, conditioning photic stimulation blocked the response to the test auditory stimulus, but no remnant EPSP was recorded to the test stimulus. 3. Type-III interaction. Same cell as in 2. Reverse interaction (A-P). Conditioning auditory stimulation evoked membrane hyperpolarization and blocked spike discharge to the photic test stimulus. A remnant EPSP was recorded, as illustrated, on the hyperpolarized membrane. Time calibration is $100 \mathrm{msec}$ unless otherwise indicated. The d-c potential leve's for the upper, intracellular tracings are given at the left. Spikes in 2 and 3 have been retouched. 
blocking intervals although both inputs evoked asynchronous EPSPs with spikes. Apparently, the blocking effect had occurred before the recorded cell, either in cortex or below. There was no evidence of the relative roles of occlusion and inhibition in the blocking effect. In the type-II interaction, membrane hyperpolarization occurred in response to the conditioning stimulus, though there was again no evidence that cortical inhibitory mechanisms were responsible for the block. If synaptic activity evoked by the test stimulus reached the cell it should be seen as an EPSP on the hyperpolarized membrane. In type-II interactions, the lack of any asynchronous EPSP on the hyperpolarized membrane probably indicates that most, if not all, of the blocking effect has occurred before the recorded cell. In the type-III interaction, the block apparently is the result of inhibitory activity at the recorded cortical cell. This is shown in the lower frames of Fig. 6. Conditioning auditory stimulation evoked membrane hyperpolarization and blocked the spike discharge to the succeeding photic stimulus. A remnant asynchronous EPSP was recorded on the hyperpolarized membrane.

In summary, the type of interaction recorded depended upon which sensory input was employed as the conditioning stimulus. With conditioning photic stimuli, type-I and type-II interactions were most prevalent (16 out of 18 photic-auditory, blocking interactions). The data suggest that convergence of input occurs at central synapses in association cortex as well as in other portions of the central nervous system (e.g., thalamus and reticular formation). On the other hand, auditory stimuli did not block the cellular response to succeeding photic stimuli unless membrane hyperpolarization occurred in response to the auditory conditioning stimulus. In all auditory-photic interactions exhibiting blocking effects, remnant asynchronous EPSPs were recorded on the hyperpolarized membrane, indicating the presence of inhibition at the cortical level (type III, 4 out of 13 auditory-photic interactions). In the other nine auditory-photic interactions, membrane hyperpolarization was not evoked by the auditory stimulus and no blocking effect was observed.

Centrally Originating Input: Thalamic Stimulation. Electrodes were placed in the lateral nuclear group, either in the nucleus lateralis posterior, the nucleus suprageniculatus or the pulvinar, and this stimulating site is referred to as the LP complex. Intralaminar nuclei electrodes were usually in the centromedian nucleus, and this stimulating site is referred to as the CM complex.

Excitatory responses and inhibitory responses (membrane hyperpolariza- 
tion which blocked spike discharge and occurred in the absence of preceding spike discharge) were evoked in association cortex neurons when either of these thalamic groups were stimulated (Figs. 2, 3, Table 2). Excitatory responses were more prevalent than inhibitory responses to LP complex stimulation. The excitatory responses were short latency, synchronous EPSPs with spike discharge. The average EPSP latency for thirty-eight cells was $3.1 \mathrm{msec}$ with a range of less than 1 to $13 \mathrm{msec}$. The straight line

TABLE 2

Responstueness of Cells to Each Central Input DURING INTRACELLULAR RECORDINGS

\begin{tabular}{lccccc}
\hline \multicolumn{1}{c}{ Input } & $\mathrm{N}^{a}$ & $\begin{array}{c}\text { Excitatory } \\
\text { only }^{b} \\
\%^{c}\end{array}$ & $\begin{array}{c}\text { Inhibitory } \\
\text { only } \\
\%\end{array}$ & $\begin{array}{c}\text { Both }^{d} \\
\%\end{array}$ & $\begin{array}{c}\text { Unresponsive } \\
\%\end{array}$ \\
\hline LP complex & 79 & 42 & 4 & 6.5 & 47.5 \\
CM complex & 52 & 27 & 13.5 & 9.5 & 50 \\
TCR & 51 & 59 & 12 & 13.5 & 15.5 \\
IDR & 51 & 33 & 6 & 4 & 57 \\
\hline
\end{tabular}

${ }^{a} \mathrm{~N}$ represents the total number of cells studied in each category.

${ }^{b}$ Includes eleven cells which showed only EPSPs and no spike discharge to one or more central stimuli. Six of these "EPSP only" responses occurred during the TCR.

$c \%$ refers to the percentage of cells responding in each category irrespective of whether the cell responded to any other central stimulus.

d Some of the cells exhibited excitatory and inhibitory responses. These cells are listed separately in the "Both" column.

distance from LP complex to the recording site in suprasylvian gyrus is approximately $15 \mathrm{~mm}$. Assuming an average synaptic delay of $0.5 \mathrm{msec}$, and a conduction velocity of $15-30 \mathrm{~meter} / \mathrm{sec}$, similar to that found in the primary visual pathway, (38), then latencies of 1-2 msec indicate monosynaptic or disynaptic activation. Fifteen cells had EPSP latencies of 1 msec or less and were thus monosynaptically activated by LP complex stimulation. Only two cells were antidromically activated.

The excitatory responses to $\mathrm{CM}$ complex stimulation were asynchronous EPSPs with spike discharge. Latencies were much longer than to LP complex stimulation, averaging $11.8 \mathrm{msec}$ with a range of $5-20 \mathrm{msec}$ for nineteen cells. Inhibitory responses of similar latencies, were less common than were excitatory responses (Table 2 ).

Cells studied during LP and CM complex stimulation were also tested to photic input. Over two-thirds of the cells that responded to LP or CM complex stimulation were responsive to photic stimulation. In addition, sixteen out of fifty-one cells were responsive to LP and CM complex stim- 
ulation, fifteen of them exhibiting spike discharge to both central stimuli.

In ten cells which responded to photic and thalamic stimuli, twenty-two interactions were performed. Short-latency, excitatory responses to LP complex stimulation were blocked by conditioning photic input which evoked membrane hyperpolarization. Remnant EPSPs were recorded on the hyperpolarized membrane during these interactions (type III, six cells). When membrane hyperpolarization was not evoked by the conditioning
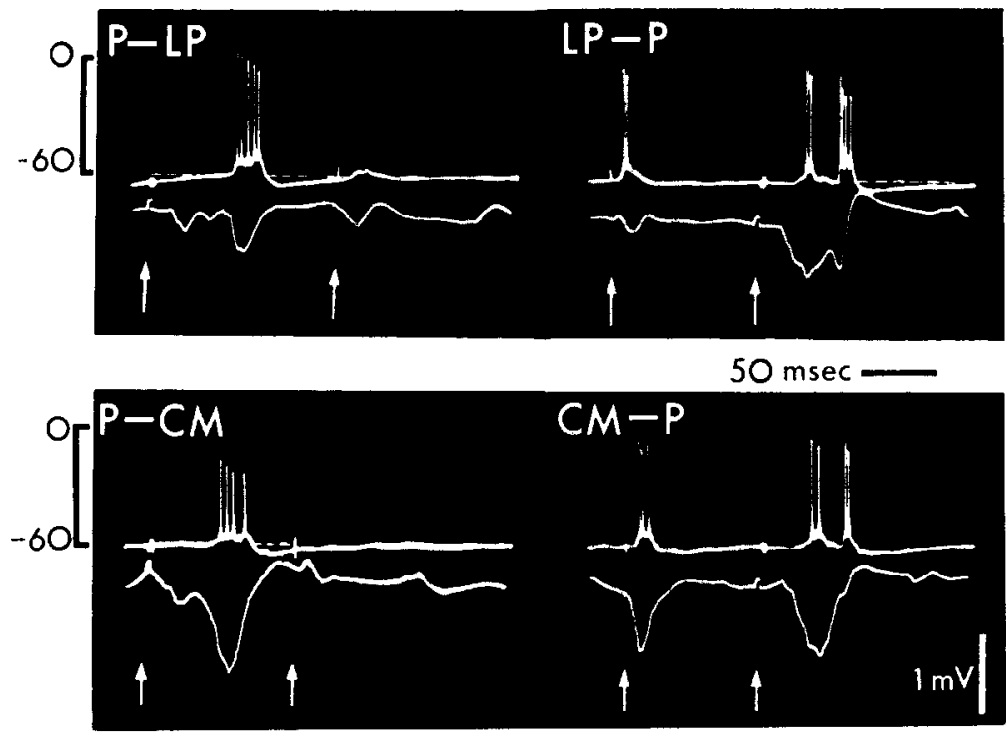

FIG. 7. Interaction between photic and thalamic inputs from a cell responsive to photic (P), LP complex (LP), and CM complex (CM) stimulation. P-LP: Type-III interaction at a conditioning-test interval of $250 \mathrm{msec}$. LP-P: No blocking effect. P-CM: Type-II interaction at a conditioning-test interval of $200 \mathrm{msec}$. CM-P: No blocking effect. Spike discharge has deteriorated slightly in P-CM.

photic stimulus, no inhibition of the short-latency, LP complex response occurred (four cells). The data strongly suggest that inhibitory interaction has occurred at the cortical level. Figure 5 is an example of this inhibitory, type-III interaction.

Conditioning photic stimuli blocked spike discharge to CM complex stimulation with and without the presence of membrane hyperpolarization in response to the conditioning stimulus. Types I, II, and III interactions were demonstrated and it appeared likely that synaptic activity evoked by CM complex stimulation was blocked before reaching cortex when conditioned by photic input. 
A lack of equivalent blocking effects was found when central thalamic stimuli were employed as conditioning stimuli. The response to a photic test stimulus was rarely blocked by conditioning LP or CM complex input. These observations are illustrated in Fig. 7 for a cell responding to all three inputs: photic, LP complex and CM complex. Conditioning thalamic stimuli did not block the cellular response to photic stimulation. Types II (P-CM) and III (P-LP) interactions were observed when light flash was the conditioning stimulus.

Centrally Originating Input: Contralateral Cortical Stimulation. Previous studies indicate that the anterior middle suprasylvian gyrus of the cat

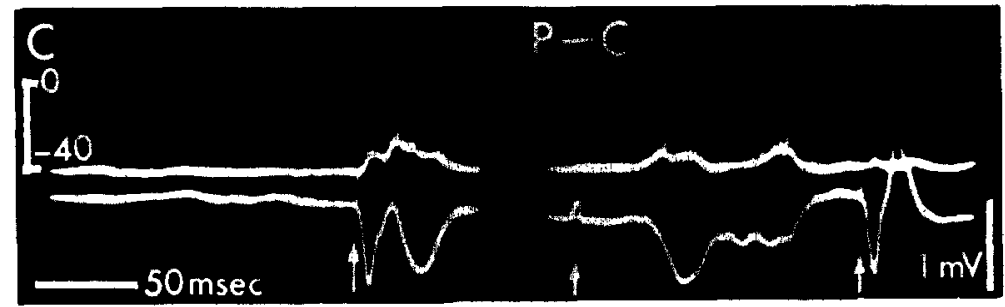

Fig. 8. Type-I interaction between photic (P) and contralateral cortical stimulation (C). Block of the IDR intracellular and surface responses by a conditioning photic stimulus (P-C). A remnant EPSP remains with the TCR. The EPSP occurs 6 msec after the cortical stimulation.

receives input from contralateral cortex via callosal and extracallosal pathways $(12,14,35)$. The following experiments describe synaptic activity evoked by contralateral cortical stimulation and the interaction effects between contralateral cortical and peripheral input. Table 2 reveals that excitatory and inhibitory responses occurred to contralateral cortical stimulation, although excitatory effects were more prevalent. Short-latency, synchronous, excitatory responses were found which had time relations similar to the surface-evoked transcallosal response (TCR). This is illustrated in Fig. 8, first frame (early EPSP). Cells were very responsive to this stimulus and six cells exhibited short-latency EPSPs without spike discharge (Table 2). Long-latency, asynchronous excitatory responses which corresponded in time course to the interhemispheric delayed response (IDR) were also seen (Fig. 8, first frame, late EPSP). Seven cells were responsive during the IDR and not during the TCR while six additional cells exhibited different slow-wave membrane potential changes during the TCR and IDR. Long-duration membrane hyperpolarization also occurred in response to contralateral cortical stimulation during both responses (Table 2). 
During interactions between responses to contralateral cortical stimulation and photic input, conditioning photic stimuli blocked the IDR intracellular response while a small EPSP remained during the TCR (Fig. 8).

\section{Discussion}

General Considerations. The asynchronous, summating EPSPs evoked by peripheral and some central inputs to association cortex have been recorded also at other cortical and subcortical sites $(20,24,26,31,32)$. These graded, depolarizing potentials of $20-80 \mathrm{msec}$ duration persist after spike discharge, and thus their long time course cannot he attributed to a passive electrical process of the postsynaptic membrane. They probably represent prolonged transmitter action resulting from temporally dispersed synaptic bombardment. The irregular, steplike configuration of thesc EPSPs argues against prolonged transmitter release by a single synchronous presynaptic discharge.

The long-duration hyperpolarizing potentials evoked by different inputs are now a common finding in the cerebral cortex and other portions of the central nervous system (e.g., 2, 19, 24, 31). In the present study they have been identified as inhibitory in $20 \%$ of cells where membrane hyperpolarization was evoked by one or more stimuli. The reduced amplitude of EPSPs evoked during membrane hyperpolarization may be due to presynaptic or postsynaptic inhibition at the recorded cell, although the presence of additional inhibitory activity at previous synapses cannot be completely ruled out. The inversion of hyperpolarizing synaptic potentials to depolarizing synaptic potentials by chloride leakage clearly establishes the presence of postsynaptic inhibition at the recorded cell, and has been accomplished in the present experiments during impalements with $\mathrm{KCl}$ filled electrodes. Similar inversions of long-duration IPSPs have been recorded in hippocampal pyramidal cells (24), thalamus (6), and motor cortex (32).

In contrast to the asynchronous EPSPs discussed above, the long-duration inhibitory potentials recorded in association cortex are probably due to initial brief synaptic bombardment rather than temporally dispersed inflow. They usually have a regular, smooth configuration which suggests that there is synchronous inhibitory synaptic activity resulting in prolonged transmitter action. An exception to this smooth configuration is illustrated in Fig. 3A, where some asynchrony in the inhibitory response to LP complex stimulation was seen.

Most of the cells that exhibited long-duration hyperpolarization dis- 
played preceding spike discharge to the stimulus (Tables 1,2). However, the prevalence of inhibitory responses without preceding spike discharge to various stimuli reveals that the previous extracellular data (14) was biased in the direction of excitatory responses. Cells exhibiting inhibitory input without preceding excitatory synaptic activity ("inhibitory only" category) would be overlooked because of the low spontaneous firing rates found under chloralose anesthesia.

Evidence has been presented above which indicates that synaptic potentials contribute to the electrical activity recorded from the cortical surface, and supports the hypothesis originally proposed by Eccles (15). Similar results have been reported in hippocampal (23) and motor cortex $(25,33)$, and it appears that the surface wave represents the sum of membrane depolarizations and hyperpolarizations in cortical neurons.

Peripherally Originating Input. The activity of cells during intracellular recordings supports the previous conclusion that the cat's anterior middle suprasylvian gyrus is unequally responsive to different sensory inputs (14). Cells exhibited convergence of photic and other peripheral inputs, or were responsive to light flash alone. Over $80 \%$ of the cells studied altered their discharge pattern to diffuse light, while a decreasing order of responsiveness was found for the other peripheral inputs. The interpretation that this area of suprasylvian gyrus is predominantly influenced by photic stimulation is limited by the types of stimuli employed in these experiments. It is possible that cells would respond differently when tested to more specific stimuli within each sensory modality (e.g., patterned light, different frequencies of sound, etc.). In addition, it was difficult to establish conclusively equality of stimulus magnitudes though efforts were made to achieve maximum evoked responses to each input. It should also be emphasized that cells responded in an "all or none" manner to peripheral stimuli; they were usually not influenced by large changes in stimulus magnitude.

Over $30 \%$ of the polysensory cells studied during intracellular recordings manifested different slow-wave membrane potential changes to photic and auditory stimuli. Thus, unequal convergence also occurs upon polysensory cells. These data are in complete disagreement with the hypothesis, advanced by Albe-Fessard and Gillett (3) for the somatosensory system, and extended to other inputs by Thompson and co-workers $(36,37)$, of a common pathway of sensory input to association cortex. Such an interpretation deprives the area of any specific sensory functions and seems unlikely in view of the unequal responsiveness of cells demonstrated in our experiments. 
Cortical inhibitory mechanisms evoked by peripheral stimulation play a role in the long-duration blocking effects observed during stimulus interactions. The type-III interaction demonstrates that photic input to this area was inhibited only by conditioning auditory stimuli which evoked membrane hyperpolarization. There was no evidence that photic input was substantially blocked before it reached the recorded cell. On the other hand, type-I and type-II interactions, in which there was no evidence of inhibitory mechanisms at the cortical level, were most prevalent during interactions when light flash was the conditioning stimulus, and indicate that convergence occurred before the recorded cell, in cortex and at subcortical sites. The presence of blocking interactions in specific and nonspecific thalamic nuclei supports this interpretation $(3,9)$.

Centrally Originating Input. The demonstration of short-latency, monosynaptic and disynaptic connections between LP complex and association cortex neurons corroborates the earlier anatomical data (39). Most of the short-latency responses to LP complex stimulation were excitatory, though on occasion inhibitory responses were recorded (Fig. 1B). However, latency measurements do not indicate that there is direct thalamic inhibitory input to association cortex and cortical inhibitory neurons probably participate in this pathway. The existence of direct thalamocortical connections was verified further during interaction experiments in which cortical inhibitory mechanisms blocked thalamocortical activation. Short-latency excitatory responses to LP complex stimulation were inhibited only when membrane hyperpolarization was evoked by the conditioning stimulus, indicating that subcortical interactions have been circumvented and do not participate in the blocking effect on this response.

The CM complex stimulation evoked long-latency, excitatory or inhibitory responses, or both, and these responses are evidence of a polysynaptic pathway from nonspecific thalamus to association cortex. Morillo (28) reported similar latency measurements in his extracellular study, but he was unable to activate the same cells with LP complex and non-specific thalamic stimulation. The results of the present study are the contrary; many cells exhibited spike discharge to both central thalamic inputs. This dual control by relatively independent thalamocortical projection systems re-emphasizes that multimodal central as well as peripheral input systems synaptically bombard cortical association neurons. The different EPSP patterns evoked by the two systems may have functional significance for cells activated by numerous sources of input.

Differential unit activation during the transcallosal or interhemispheric 
delayed response supports earlier conclusions (35) that interhemispheric pathways are different for these two responses. The fact that conditioning photic stimuli can differentially block the IDR cellular and surface-recorded responses is additional evidence in favor of this interpretation.

Cellular Integrative Mechanisms in Association Cortex. The presence of multiple sources of input converging upon association cortex neurons suggests that cellular integrative mechanisms are available at the cortical level. Some of these integrative mechanisms have been elucidated in the present experiments. First, relative differences in EPSP size, duration, and synchrony displayed by the dual thalamocortical projection systems and the dual contralateral cortical inputs are probably related to the spatial distribution of these impinging inputs. The finding of different proportions of depolarizing and hyperpolarizing potentials generated by different stimuli also may be significant $(33)$. Second, other investigators $(5,30)$ indicate that the temporal patterning of neuronal output may be more important than changes in the frequency of cell discharge in the coding of incoming sensory information. Changes in the occurrence, duration, and size of longduration inhibitory potentials, as observed in our experiments, undoubtedly assume a prominent role in such mechanisms. Third, long-duration inhibitory mechanisms are effective in reducing the responsiveness of cortical cells to subsequent inputs. Especially potent inputs producing such inhibitory effects in association cortex appear to be capable, at certain moments, of doing likewise at other levels of the neuraxis. The responsiveness of cortical cells may then reflect the widespread inhibitory effects.

\section{References}

1. Adrian, R. H. 1956. The effect of internal and external potassium concentration on the membrane potential of frog muscle. J. Physiol. London 133: 631-658.

2. Albe-Fessard, D., and P. Buser. 1955. Activités intracellulaires recueillies dans le cortex sigmoïde du chat: participation des neurones pyramidaux au "potentiel évoqué" somesthésique. J. Physiol. Paris 47: 67-69.

3. Albe-Fessard, D., and E. Gillett. 1961. Convergences d'afferences d'origines corticale et peripherique vers le centre médian du chat anesthésié ou eveille. Electroencephalog. Clin. Neurophysiol. 13: 257-269.

4. Amassian, V. E., and R. V. Devito. 1954. Unit activity in reticular formation and nearby structures. J. Neurophysiol. 17: 575-603.

5. Amassian, V. E., and H. J. Waller. 1958. Spatiotemporal patterns of activity in individual reticular neurons, pp. 69-110. In "Reticular Formation of the Brain." H. H. Jasper, L. D. Proctor, R. S. Knighton, W. C. Noshay, and R. T. Costello [eds.]. Little, Brown, Boston, Massachusetts.

6. Anderson, P., C. M. Brooks, and J. C. Eccless. 1964. Electrical responses of 
the ventrobasal nucleus of the thalamus, pp. 100-113. In "Lectures on the Diencephalon." W. Bargmann and J. P. Schadé [eds.]. Elsevier, Amsterdam.

7. Bell, C., G. Sierra, N. Buendia, and J. P. Segundo. 1964. Sensory properties of neurons in the mesencephalic reticular formation. J. Neurophysiol. 27: 961987.

8. BIGNALL, K. E., and L. T. RutLEDGE. 1964. Origin of a photically evoked afterdischarge in cat visual cortex. J. Neurophysiol. 27: 1048-1062.

9. Borenstein, P., J. Bruner, and P. Buser. 1959. Organisation neuronique et convergences hétérosensorielles dans le complexe latéral postérieur "associatif" du thalamus chez le chat. J. Physiol. Paris 51: 413-414.

10. Coombs, J. S., D. R. Curtis, and J. C. Eccles. 1957. The interpretation of spike potentials of motoneurones. J. Physiol. London 139: 198-231.

11. Coombs, J. S., J. C. Eccles, and P. Fatt. 1955. The specific ionic conductances and the ionic movements across the motoneural membrane that produce the inhibitory post-synaptic potential. J. Physiol. London 130: 326-373.

12. Curtis, H. J. 1940. Intercortical connections of corpus callosum as indicated by evoked potentials. J. Neurophysiol. 3: 407-413.

13. Dubner, R., and L. T. Rutledge. 1964a. Intracellular responses to peripheral and central stimuli in association cortex of cat. Federation Proc. 23 (2): 210.

14. Dubner, R., and L. T. Rutledge. 1964b. Recording and analysis of converging input upon neurons in cat association cortex. J. Neurophysiol. 27: 620-634.

15. Eccles, J. C. 1951. Interpretation of action potentials evoked in the cerebral cortex. Electroencephalog. Clin. Neurophysiol. 3: 449-464.

16. Eccles, J. C. 1957. "The Physiology of Nerve Cells." Johns Hopkins Press, Baltimore, Maryland.

17. Eccles, J. C. 1961. The mechanism of synaptic transmission. Ergbn. Physiol. 51: $299-430$.

18. Fuortes, M. G. F., K. Frank, and M. C. Becker. 1957. Steps in the production of motoneuron spikes. J. Gen. Physiol. 40: 735-752.

19. Granit, R., and G. C. Phillips. 1956. Excitatory and inhibitory processes acting upon individual Purkinje cells of the cerebellum in cats. J. Physiol. London 133: 520-547.

20. Hunt, C. C., and M. Kuno. 1959. Properties of spinal interneurones. J. Physiol. London 147: 346-363.

21. Jasper, H. H., and C. AJmone Marsan. 1954. "A Stereotaxic Atlas of the Diencephalon of the Cat." National Research Council of Canada, Ottawa.

22. KANDEL, E. R, and W. A. Spencer. 1961a. Electrophysiology of hippocampal neurons. II. After-potentials and repetitive firing. J. Neurophysiol. 24: 243-259.

23. Kanded, E. R., and W. A. SPEncer. 1961b. Excitation and inhibition of single pyramidal cells during hippocampal seizure. Exptl. Neurol. 4: 162-179.

24. Kandel, E. R., W. A. Spencer, and F. J. Brinley, JR. 1961. Electrophysiology of hippocampal neurons. I. Sequential invasion and synaptic organization. J. Neurophysiol. 24: 225-242.

25. Klee, M. R., K. Offenloch, and J. Tigges. 1964. Cross-correlation analysis of electroencephalographic potentials and slow membrane transients. Science 147: 519-521. 
26. Limans'kII, Yu. P. 1963. Characteristics of afferent convergence on neurons of the medullary reticular formation. Fed. Proc. 22: T1090-T1093.

27. MaGNI, F., and W. D. WiLLIS. 1963. Identification of reticular formation neurons by intracellular recording. Arch. Ital. Biol. 101: 681-702.

28. MoRILlo, A. 1961. Microelectrode analysis of some functional characteristics and inter-relationships of specific, association and non-specific thalamocortical systems. Electroencephalog. Clin. Neurophysiol. 13: 9-20.

29. Poggio, G. F., and V. B. Mountcastle. 1960. A study of the functional contributions of the lemniscal and spinothalamic systems to somatic sensibility. Johns Hopkins Hosp. Bull. 106: 266-316.

30. Poggio, G. F, and L. J. Viernstein. 1964. Time series analysis of impulse sequences of thalamic somatic sensory neurons. J. Neurophysiol. 27: 517-545.

31. Purpura, D. P., and B. Cohen. 1962. Intracellular recording from thalamic neurons during recruiting responses. J. Neurophysiol. 25: 621-635.

32. Purpura, D. P., and R. J. Shofer. 1964. Cortical intracellular potentials during augmenting and recruiting responses. I. Effects of injected hyperpolarizing currents on evoked membrane potential changes. $J$. Neurophysiol. 27: 117-132.

33. Purpura, D. P., R. J. Shofer, and F. S. Musgrave. 1964. Cortical intracellular potentials during augmenting and recruiting responses. Il. Patterns of synaptic activities in pyramidal and nonpyramidal tract neurons. $J$. Neurophysiol. 27: 133-151.

34. Rutledge, L. T., and T. T. Kennedy. 1960. Extracallosal delayed responses to cortical stimulation in chloralosed cat. $J$. Neurophysiol. 23: 188-196.

35. Rutledge, L. T., and T. T. Kennedx. 1961. Brain-stem and cortical interactions in the interhemispheric delayed response. Exptl. Neurol. 4: 470-483.

36. Thompson, R. F., R. H. Johnson, and J. J. Hoopes. 1963. Organization of auditory, somatic sensory, and visual projection to association fields of cerebral cortex in the cat. J. Neurophysiol. 26: 343-364.

37. Thоmpson, R. F., H. E. Sмiтн, and D. Bliss. 1963. Auditory, somatic sensory, and visual response interactions and interrelations in association and primary cortical fields of the cat. J. Neurophysiol. 26: 365-378.

38. Vastola, E. F. 1961. A dircet pathway from lateral geniculate body to association cortex. J. Neurophysiol. 24: 469-487.

39. Waller, W. H., and R. W. Barris. 1937. Relationships of thalamic nuclei to the cerebral cortex in the cat. J. Comp. Neurol. 67: 317-339. 